\title{
Estudos sobre accountability no Brasil: meta-análise de periódicos brasileiros das áreas de administração, administração pública, ciência política e ciências sociais
}

\author{
Anny Karine de Medeiros \\ Escola de Administração de Empresas de São Paulo da Fundação Getulio Vargas (EAESP/FGV) \\ Tamara Ilinsky Crantschaninov \\ Escola de Administração de Empresas de São Paulo da Fundação Getulio Vargas (EAESP/FGV) \\ Fernanda Cristina da Silva \\ Escola de Administração de Empresas de São Paulo da Fundação Getulio Vargas (EAESP/FGV)
}

\begin{abstract}
O artigo tem por objetivo identificar como o termo accountability tem sido tratado na literatura brasileira, considerando periódicos das áreas de administração, administração pública, ciência política e ciências sociais. Foram identificados e analisados 53 artigos. Os resultados indicaram que o tema ganhou mais relevância nos estudos a partir de 2006, tendo a Revista de Administração Pública (RAP) o maior número de publicações. Os artigos analisados, em sua maioria, são empíricos, e muitos apenas citam o termo accountability, sem defini-lo ou analisá-lo. Constatou-se que os artigos que discutem o tema apresentam uma clara confusão sobre o seu significado, sendo "responsabilização" e "prestação de contas" os termos mais citados nas definições. Acredita-se que este estudo torna-se relevante por, além de demonstrar a significação dada ao termo, também apontar os limites de sua utilização.
\end{abstract}

Palavras-chave: accountability; meta-análise; responsabilização.

Los estudios sobre accountability en Brasil: meta-análisis de publicaciones periódicas brasileñas de las áreas de administración, administración pública, ciencias políticas y ciencias sociales Este artículo tiene como objetivo identificar cómo lo término accountability ha sido tratado en la literatura brasileña, considerando publicaciones periódicas de las áreas de administración, administración pública, ciencias políticas y ciencias sociales. Se identificaron y analizaron 53 artículos. Los resultados indicaron que el tema ganó mayor importancia en los estúdios a partir de 2006, y la Revista de Administração Pública (RAP) tiene el mayor número de publicaciones. Los artículos analizados, en su mayoría, son empíricos, y muchos sólo mencionan el término, sin definirlo ni analizarlo. Los artículos que tratan el tema tienen una clara confusión sobre su significado, siendo los términos "responsable"

Artigo recebido em 10 mar. 2012 e aceito em 15 fev. 2013.

Rev. Adm. Pública - Rio de Janeiro 47(3):745-775, maio/jun. 2013 
y "renidición de cuentas" los más citados em las definiciones. Se cree que este estudio cobra relevancia ya que, además de demostrar el significado dado al término, evidencia los límites de su uso.

Palabras Clave: accountability; meta-análisis; responsabilidad.

Studies on accountability in Brazil: meta-analysis of Brazilians periodicals of areas of administration, public administration, political science and social science

This article aims to identify how the term accountability has been treated in Brazilian literature, considering periodicals of the areas of administration, public administration, political science and social sciences. 53 articles were identified and analyzed. The results indicated that the issue gained more prominence in studies from 2006, and the Revista de Administração Pública (RAP) has the highest number of publications. The articles analyzed, mostly, are empirical, and many just mentioning the term accountability, without defining it or analyze it. It was found that the articles that discuss the issue have a clear confusion about its meaning, being "responsible" and "account render" the terms most frequently cited as definitions. It is believed that this study becomes relevant because, besides demonstrating the meaning given to the term, also points out the limits of its use.

KEYWORDs: accountability; meta-analysis; responsibility.

\section{Introdução}

O termo accountability ganha força no Brasil no mesmo momento em que a democracia se torna princípio fundamental do sistema político, após a queda do regime militar. Desde então, o termo circunda a literatura em companhia de expressões como controle social, participação e a própria democratização do Estado. Apesar de sua notoriedade, ainda não existe uma palavra no idioma brasileiro que traduza completamente o termo, gerando uma série de debates e diferentes interpretações sobre o mesmo. Pinho e Sacramento (2009), no artigo "Accountability: já podemos traduzi-la para o português?”, buscaram verificar se já era possível encontrar sinônimos em português para o termo, a partir da incorporação da accountability como valor cultural e político no Brasil. Apesar de não responderem conclusivamente a questão proposta, os autores apontam um pequeno avanço quanto à conceituação da accountability no Brasil, mesmo que uma verdadeira cultura de accountability ainda esteja longe de ser construída no país.

A partir deste cenário, encontrou-se a necessidade de identificar como o termo tem sido estudado na literatura acadêmica brasileira, considerando os principais periódicos das áreas de administração, administração pública, ciência política e ciências sociais. Para tanto, espera-se organizar as abordagens e situar o termo, promovendo um panorama de seu uso em diferentes estudos.

A importância da apresentação desse panorama deve-se não só à popularização do termo e seu uso frequente em diversas áreas do conhecimento, sobretudo aquelas ligadas às questões sociais, mas também a necessidade de desfazer, ainda que minimamente, o "novelo de lã" que se criou em sua volta. Isto porque o maciço uso do termo, sem o cuidado de sedimentar o conceito envolvido, muitas vezes faz com que o mesmo não reflita a ideia originária, sendo relacionada a diversos outros conceitos. Exemplo disso é o fato de a palavra accountabi- 
lity poder ser utilizada como legitimador de determinadas ações governamentais, mas, com a dificuldade de expressar exatamente seu significado, esta se torna vazia ou contraditória.

Assim, a fim de atender ao objetivo exposto, o artigo está organizado da seguinte maneira: após esta introdução, é apresentada uma breve revisão teórica acerca do debate sobre o conceito e a utilização do termo accountability. Posteriormente, são detalhados os procedimentos metodológicos que conduziram a pesquisa. Em seguida, os estudos analisados são caracterizados em linhas gerais, para depois serem organizados segundo abordagens, conceitos e experiências. A partir de então, foi elaborado um panorama geral do uso do conceito nos estudos brasileiros, seguido, por fim, das conclusões e considerações finais.

\section{Marco teórico: a discussão sobre o conceito e a utilização do termo accountability}

Antes de apresentar a discussão sobre os estudos referentes ao tema accountability na literatura brasileira, serão situados alguns dos principais pontos que permeiam a discussão internacional e nacional sobre o mesmo.

\subsection{A falta de consenso quanto à significação de accountability}

Apesar de não haver consenso quanto à tradução do termo accountability para o português (Campos, 1990; Pinho e Sacramento, 2009) e também para outros idiomas (Sacramento, 2005), sua identificação como responsabilização teve origem nas nações anglo-saxãs, tornando-se central na história política dos Estados Unidos (Ceneviva, 2006; Clad, 2000; Sacramento, 2005).

Além da tradução, falta ao termo uma definição consensual quanto ao seu significado e uma clara delimitação teórica, tendo em vista que as diversas definições encontradas na literatura tendem a variar acentuadamente não apenas de autor para autor, mas também conforme a tradição disciplinar no qual o trabalho se insere (Ceneviva, 2006). Dessa maneira, conforme salientado por Mainwaring (2003:6), "accountability is far-from-consensual concept", ${ }^{1}$ mesmo na língua inglesa.

Mainwaring (2003) considera que existem cinco grandes campos de debate conceitual sobre o termo, que giram basicamente sobre quão ampla deve ser esta conceituação: se absolutamente todas as atividades que envolvem oficiais públicos devem estar sob a rubrica da accountability, visto que suas ações não dependem somente de suas habilidades pessoais, e também do contexto em que ocorrem e das ações dos demais atores; se os oficiais públicos devem ser accountables somente em relação aos termos legais, ou se também devem ser questionados para além da lei; a possibilidade de imposição de sanções como parte fundamental

\footnotetext{
1 “Accountability está longe de ser um conceito consensual." (tradução nossa)
} 
do conceito de accountability (no caso, se não existe a possibilidade de imposição de sanção, o conceito não seria válido); se a accountability só seria válida na relação agente-principal; ${ }^{2} \mathrm{e}$ quais atores podem servir como mecanismo de accountabilty, visto que, numa definição mais informal do termo, qualquer ator poderia pedir contas para qualquer outro ator, mesmo fora de uma relação de agente-principal. Essas cinco categorias são demonstrativas do quão largo e nebuloso é o desafio de conceituação da accountability.

Abrucio e Loureiro (2004:75) afirmam que "normalmente a literatura sobre accountability trata do controle dos atos dos governantes em relação ao programa de governo, à corrupção ou à preservação de direitos fundamentais dos cidadãos". Mas segundo os autores, o tema recentemente também tem sido analisado no contexto da reforma do Estado, especialmente nas discussões sobre como transparência e responsabilização podem melhorar a eficiência da ação governamental.

Para Denhardt e Denhardt (2003), a accountability é um tema complexo, mas tratado de forma simplista pelas teorias de administração, tanto na escola clássica (Old Public Administration) quanto na Nova Gestão Pública (New Public Management), já que para ambas o administrador público é visto como empreendedor, sendo accountable em termos de eficiência, custos e responsividade para com as forças de mercado. É no Novo Serviço Público (New Public Service) que o conceito de accountability retoma as noções de cidadania e interesse público (Denhardt e Denhardt, 2003).

Segundo o Centro Latino-Americano de Administração para o Desenvolvimento (Clad) (2000), o conceito de accountability significa que governo tem a obrigação de prestar contas à sociedade. Porém, sua realização depende da capacidade dos cidadãos para atuar na definição de metas coletivas de sua sociedade, já que a indiferença da população com relação à política pode inviabilizar o processo de accountability; e da construção de mecanismos institucionais para garantir o controle público das ações dos governantes, não apenas por meio de eleições, mas também durante todo o prazo de vigência dos representantes.

\subsection{Accountability e democracia}

Conforme o conselho científico do Clad (2000), a accountability está inserida em um sistema maior, no regime democrático moderno, cujos princípios centrais são a soberania popular (em que o poder emana do povo) e o controle dos governantes para os governados. Abrucio e Loureiro (2004:81) acrescentam um terceiro princípio, afirmando que na democracia o "Estado deve ser regido por regras que delimitem seu campo de atuação em prol da defesa de direitos básicos dos cidadãos, tanto individuais como coletivos". Para o Clad (2000), é para atender aos dois primeiros princípios que as eleições se tornaram o principal instrumento de prestação de contas do governo aos cidadãos.

\footnotetext{
${ }^{2}$ A relação agente-principal é estabelecida como uma parte imbuída do poder de decisão, enquanto outra é responsável pela implementação daquela decisão. As relações entre eleitores (principal) e políticos eleitos (agente) é um típico caso deste sistema - os eleitores, a partir do seu poder de voto, permitem que os políticos atuem em seu nome. Contudo, os eleitores não controlam os políticos o tempo todo, o que pode gerar problemas de controle sobre suas ações - e então se estabelece o debate sobre accountability.
} 
Assim, parte-se da constatação de que a accountability é tema fundamental para a teoria democrática (Dunn e Legge, 2000 apud Denhardt e Denhardt, 2003). O debate internacional sobre o tema acontece há décadas, e se desenvolve pela dicotomia entre administração burocrática e democracia, já que o desenvolvimento de uma interfere na outra. Alguns autores (Denhardt e Denhardt, 2003), para demonstrar como o conceito de accountability se modifica ao longo do tempo, remontam à década de 1940, na qual o profissionalismo era considerado o melhor caminho para se atingir a accountability (Friedrich, 1940, apud Denhardt e Denhardt, 2003). Isto porque, seguindo o argumento de Friedrich (1940, apud Denhardt e Denhardt, 2003), a complexidade dos problemas governamentais e a ampliação do fator de discricionariedade reforçam a importância do conhecimento técnico e científico para a responsividade administrativa. Já Herman Finer (1941, apud Denhardt e Denhardt, 2003) traz noção contrária, ao afirmar que controles externos são o melhor (e único) método para garantir accountability administrativa em democracias, reforçando o poder de gestão dos governantes eleitos, por responderem diretamente a seu eleitorado, e identificando a discricionariedade como nociva à democracia.

\subsection{Formas de accountability}

Guilhermino O’Donnell (1998) foi o pioneiro na conceituação das formas de accountability (Ceneviva, 2006). Conforme este autor, a accountability vertical corresponde às "ações realizadas, individualmente ou por algum tipo de ação organizada e/ou coletiva, com referência àqueles que ocupam posições em instituições do Estado, eleitos ou não" (O'Donnell, 1998:28). As eleições, as reivindicações sociais normalmente proferidas e a cobertura regular

pela mídia dessas reinvindicações e de atos supostamente ilícitos de autoridades públicas são os mecanismos desta dimensão da accountability (O’Donnell, 1998).

Já accountability horizontal é definida por O’Donnell (1998:40) como

a existência de agências estatais que têm o direito e o poder legal e que estão de fato dispostas e capacitadas para realizar ações, que vão desde a supervisão de rotina a sanções legais ou até impeachment contra ações ou emissões de outros agentes ou agências do Estado que possam ser qualificadas como delituosas.

Segundo O’Donnell (1998), os mecanismos desta dimensão incluem as ações das instituições clássicas do Executivo, do Legislativo e do Judiciário e ainda das várias agências de supervisão, como os ombudsmen e as instâncias responsáveis pela fiscalização das prestações de contas.

Apesar da classificação de O’Donnell ser considerada uma das principais referências na literatura de ciência política (Ceneviva, 2006; Abrucio e Loureiro, 2004), estudos empíricos têm colocado em evidência algumas limitações e problemas em sua conceituação (Ceneviva, 2006). Moreno e colaboradores (2003 apud Ceneviva, 2006) questionam a clareza e as distinções das relações de accountability apresentada na classificação de O'Donnell (1998), pois se, por um lado, a accountability vertical exprime a ideia de hierarquia, por outro, a accountability 
horizontal se refere às relações de independência e semelhança que não dão conta das relações intraestatais. Dessa forma, muitas vezes a ideia de horizontalidade se torna inapropriada, pois muitas relações entre agentes públicos ou entre agências estatais são do tipo principal-agente, em que se enquadraria melhor a imagem de verticalidade, dada a hierarquia da relação.

Ainda segundo Ceneviva (2006:6), “a correspondência que O’Donnell estabelece entre relações horizontais e verticais, de um lado, e formas de accountability intraestatais e eleitorais (e societais), de outro, mostra-se inadequada". Segundo o autor, não se pode igualar accountability horizontal com accountability intraestatal tendo em vista que algumas relações intraestatais são, na verdade, verticais. Mainwaring (2003) também questiona o relacionamento entre accountability vertical e horizontal, principalmente ao adicionar discussões à divisão clássica de O'Donnell (1998), como a accountability de parlamentares aos ministros ou chefes de gabinete. Kenney (2003) se junta a esta discussão ao dizer que, apesar da definição de O’Donnell ser bastante clara, seu escopo não é - ou seja, ainda é preciso discutir exatamente em quais temas e como será exercida a accountability.

Outro tipo de classificação presente na literatura é a apresentada por Romzek e Ingraham (2000), que diferenciam quatro tipos "primários" de accountability, variando entre forças internas e externas, e maiores ou menores níveis de autonomia individual, sendo eles: (1) accountability hierárquico (hierarchical accountability), baseado na supervisão, portanto com baixa autonomia; (2) accountability legal (legal accountability), baseado na fiscalização externa (auditorias) e estruturas legislativas; (3) accountability profissional (professional accountability), baseado em altos níveis de autonomia, nos quais os indivíduos baseiam sua decisão em normas internas; e (4) accountability política (political accountability), baseado em atores externos, como governantes eleitos, opinião pública, entre outros (Romzek e Ingraham, 2000:242). Para os autores, há frequentes mudanças de ênfase e prioridade entre os tipos de accountability.

Abrucio e Loureiro (2004) apresentam outra classificação das formas de accountability, que, apesar de não ter uma grande divergência com aquelas construídas por outros autores, como Guilhermino O’Donnell (1998) e Romzek e Ingraham (2000), apresenta outra maneira de observar o processo de responsabilização democrática. Enquanto O'Donnell (1998) diferencia as formas de accountability a partir da dimensão espacial das relações e Romzek e Ingraham (2000) a partir das forças internas e externas, e maiores ou menores níveis de autonomia individual no processo de accountability, Abrucio e Loureiro (2004) apresentam formas de accountability que se diferenciam entre si na medida em que cada uma delas busca fundamentalmente um dos objetivos básicos do ideal democrático.

Os tipos de accountability democrática ${ }^{3}$ apresentados por Abrucio e Loureiro (2004) são: (i) accountability eleitoral, garantidor da soberania popular; (ii) controle institucional durante o mandato, que fornece os mecanismos de fiscalização contínua dos representantes eleitos e da alta burocracia com responsabilidade decisória; e (iii) criação de regras estatais

\footnotetext{
${ }^{3}$ Abrucio e Loureiro (2005:80), baseando-se em Haggard (1996), afirmam que a accountability democrática emerge no contexto da chamada segunda geração de reformas do Estado, "que objetiva tornar os governos não só mais eficientes no provimento de suas políticas públicas, mas também mais responsivos às demandas dos eleitores".
} 
intertemporais a fim de garantir os direitos dos indivíduos e da coletividade que não podem simplesmente ser alterados pelo governo de ocasião.

Segundo os autores, esses tipos de accountability ocorrem em todos os países democráticos, com maior ou menor grau de sucesso, mas sua consecução depende da "utilização de instrumentos institucionais e da existência de condições mais gerais (sociais, políticas, culturais etc.), capazes de dar um alicerce estrutural à democracia e as suas formas de responsabilização política" (Abrucio e Loureiro, 2004:81-82). O quadro 1 apresenta resumidamente as formas de accountability propostas por Abrucio e Loureiro (2004).

\section{Quadro 1}

\section{Accountability democrática}

\begin{tabular}{|c|c|c|}
\hline $\begin{array}{l}\text { Formas de } \\
\text { Accountability }\end{array}$ & Instrumentos & Condições \\
\hline Processo Eleitoral & 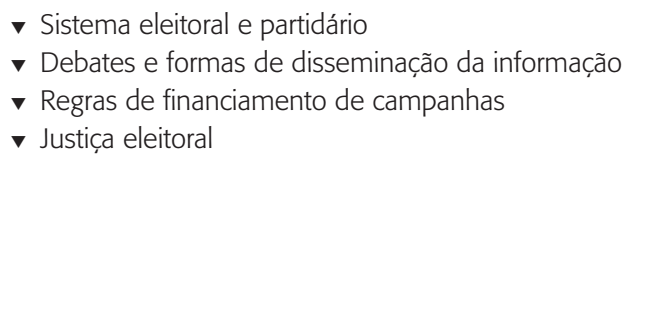 & $\begin{array}{l}\text { v Direitos políticos básicos de associação, de } \\
\text { votar e ser votado } \\
\text { v Pluralismo de ideias (crenças ideológicas e } \\
\text { religiosas) } \\
\text { v Imprensa livre e possibilidade de se obter } \\
\text { diversidade de informações } \\
\text { v Independência e controle mútuo entre os } \\
\text { poderes }\end{array}$ \\
\hline $\begin{array}{l}\text { Controle institu- } \\
\text { cional durante o } \\
\text { mandato }\end{array}$ & 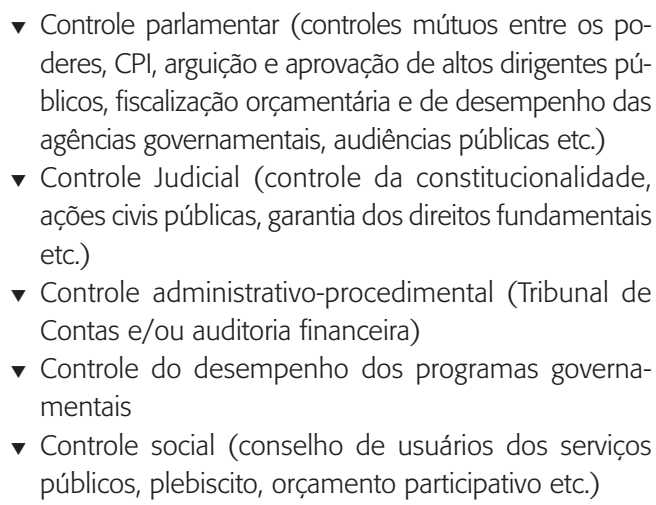 & 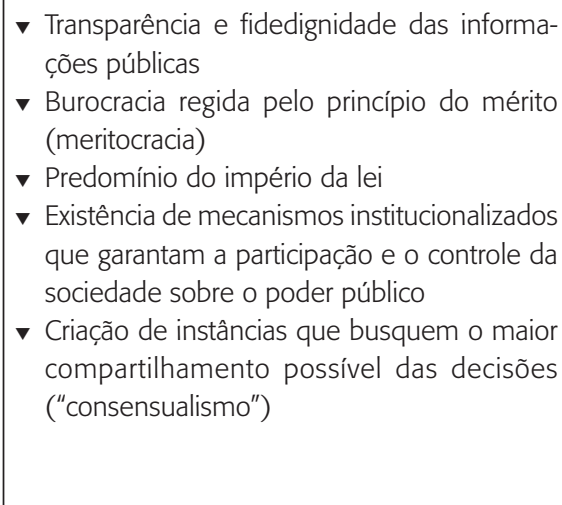 \\
\hline $\begin{array}{l}\text { Regras estatais } \\
\text { intertemporais }\end{array}$ & 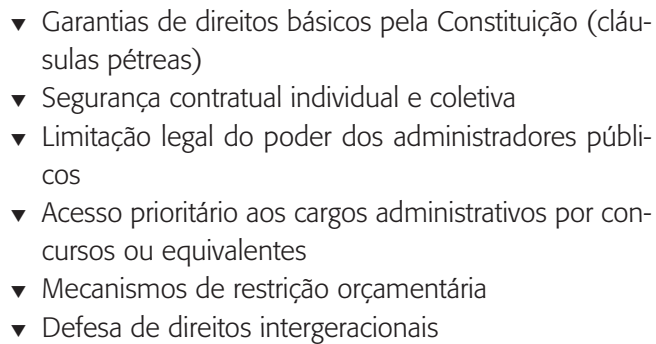 & \\
\hline
\end{tabular}

Fonte: Abrucio e Loureiro (2004:81-82). 
Apesar de existirem outras nomenclaturas para as diferentes formas de accountability, que podem se basear em critérios diversos de diferenciação, considera-se que a classificação de Abrucio e Loureiro (2004) integra os principais instrumentos de accountability presentes em outras classificações, ainda mais por representar um esforço da literatura brasileira de sistematização.

\section{Procedimentos metodológicos}

Este estudo, de cunho descritivo, se baseou em uma meta-análise ${ }^{4}$ de artigos publicados no Brasil e que tratavam do tema "accountability" como questão principal ou adjacente. Foram escolhidos artigos de três áreas de avaliação listadas na Coordenação de Aperfeiçoamento de Pessoal de Nível Superior (Capes), sendo elas: “Administração, Ciências Contábeis e Turismo", "Ciência Política e Relações Internacionais" e "Ciências Sociais Aplicadas I". A partir de uma listagem inicial dos periódicos das três áreas relacionados ao tema, foram selecionados aqueles enquadrados nas categorias "A1" até "B2". Este recorte se deu para a tentativa de analisar artigos de maior circulação e reconhecimento no meio acadêmico, ou seja, captar as utilizações de "accountability" mais difundidas. Nesta fase, também foram selecionados somente os periódicos com base em dados disponíveis no "Scielo", pela mesma razão.

A partir desta segunda listagem, foram selecionados os artigos das publicações que tinham o termo accountability como palavra indexada, de acordo com a base de dados do Scielo. ${ }^{5}$ Posteriormente, todos os artigos encontrados foram caracterizados e em seguida analisados quanto aos conceitos, experiências analisadas e abordagens sobre accountability. Por fim, os resultados encontrados nas fases anteriores foram sintetizados, sendo elaborado um panorama geral sobre o uso do termo accountability nos estudos brasileiros.

A figura 1 sumariza os procedimentos utilizados para a investigação proposta neste estudo.

\footnotetext{
${ }^{4}$ A meta-análise, segundo Pereira (2004), objetiva acumular resultados de vários estudos para se chegar a uma apresentação mais acurada dos conhecimentos em determinada área de pesquisa. Assim, a meta-análise surge para combinar, de forma quantitativa, os resultados de vários estudos, objetivando controlar o viés e a subjetividade das análises qualitativas.

${ }^{5} \mathrm{O}$ procedimento iniciou-se pelo site <www.scielo.br/? lng $=$ pt $>$, acessado no mês de outubro de 2011 . Em seguida, o periódico em questão foi procurado no campo "Pesquisa de Títulos". Na página interna da revista, dentro do portal Scielo, o termo accountability foi procurado na pesquisa, tendo como filtro as opções "Todos os índices" e "Neste Periódico".
} 


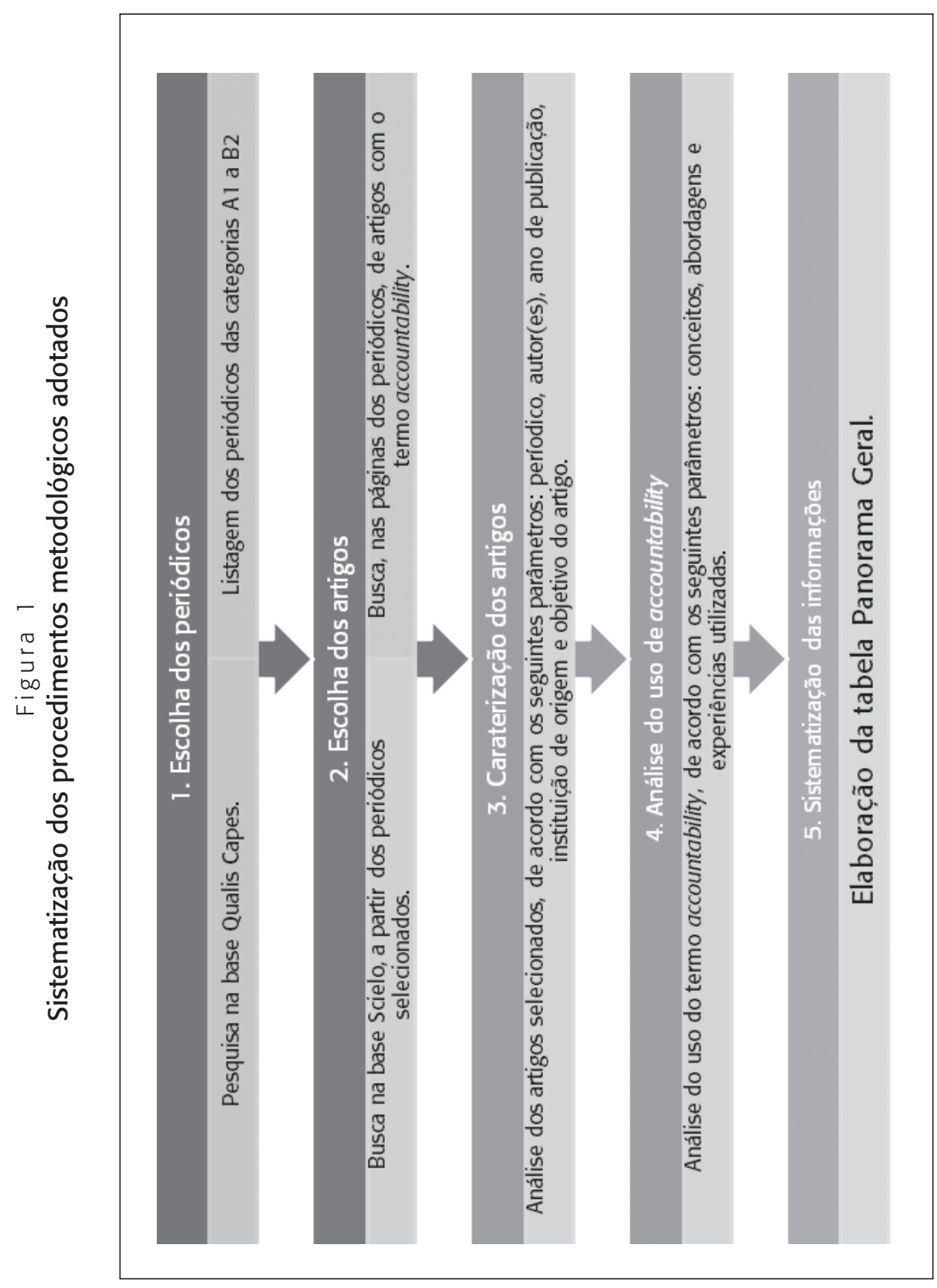

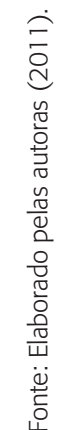


Apesar dos esforços de sistematização das informações disponíveis, este estudo é limitado em seu número de artigos e periódicos analisados em virtude da própria escassez de trabalhos publicados nas fontes pesquisadas, já que poucos foram os artigos com a palavra-chave accountability. O fato de serem poucos, entretanto, não desqualifica a análise do uso do termo, já que são utilizadas as revistas de maior importância para os respectivos campos analisados neste estudo de conhecimento.

Os procedimentos metodológicos aqui apresentados não buscam esgotar o tema, e sim aprofundar o estudo do conceito de accountability, a fim de contribuir para seu melhor entendimento.

\section{Apresentação dos resultados}

\subsection{Caracterização dos estudos}

Esta seção tem por objetivo identificar se existe concentração em relação aos artigos analisados no que se refere ao ano de publicação, aos autores, às instituições de origem, aos periódicos de publicação, à natureza dos trabalhos e aos métodos utilizados.

Ao todo, o método acima detalhado permitiu a identificação de 53 artigos, datando de 1991 até 2011, de acordo com figura 2:

Figura 2

Número de artigos publicados por ano

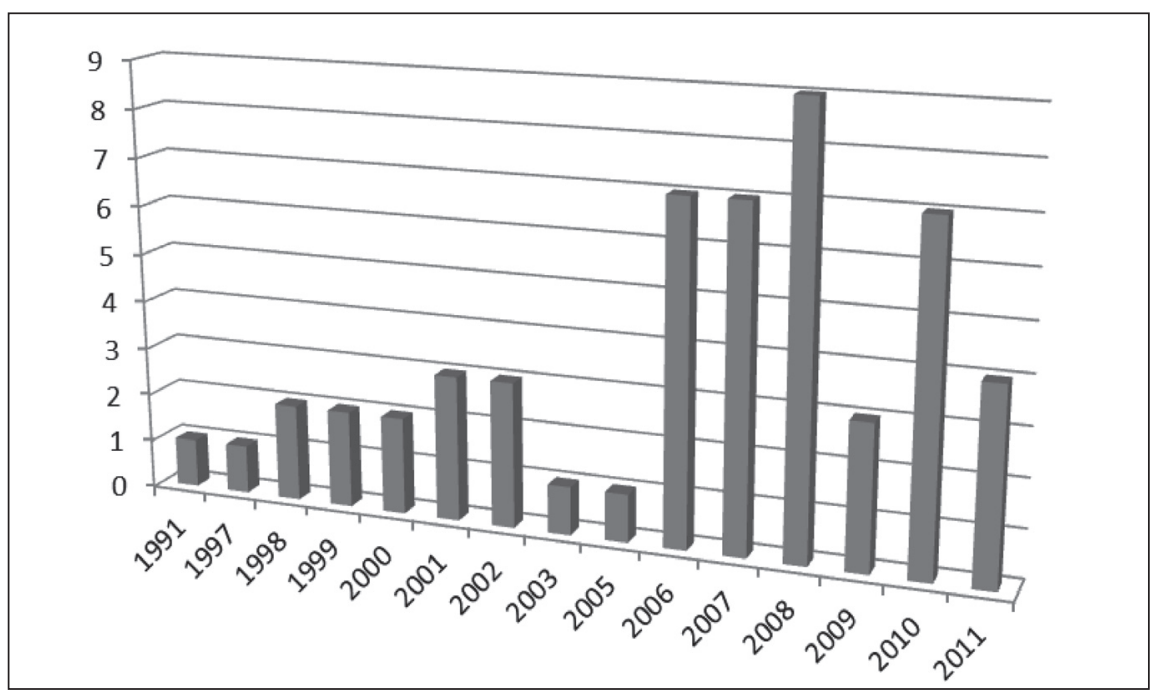

Fonte: Dados da pesquisa (2011). 
A figura 2 aponta maior concentração de artigos que tratam o tema accountability entre os anos de 2006 e 2011. É importante considerar que o método de pesquisa por meio digital, aplicado na presente pesquisa, pode ter favorecido o aparecimento desta concentração, já que o desenvolvimento tecnológico permitiu maior acesso aos periódicos, sobretudo neste período, mas a baixa presença de artigos nos anos anteriores, 2004 e 2005, reforça a percepção de que a partir de 2006 houve maior destaque para o tema.

O tema é tratado por diversos autores, sendo a maior parte dos artigos escrita individualmente. Sobre os autores, poucos se repetiram, como Luis Felipe Miguel, que aparece em artigos de quatro diferentes revistas, ${ }^{6}$ e Adam Przeworski, Adriana Maria Procópio de Araújo, Carlos Alberto Grespan Bonacim, Fernando Luiz Abrucio, José Antônio Gomes de Pinho e Marcus André Melo, que aparecem em ao menos dois artigos diferentes, como coautores, ou único autor por duas vezes, caso de Marcus André Melo.

No mesmo sentido, os artigos apresentaram variedade de instituições de origem, demonstrando não haver concentração em apenas uma. Durante a tabulação dos dados, quando a instituição não era citada no próprio artigo, e havia mais de uma instituição vinculada ao currículo Lattes do autor, optou-se por aquela instituição que possuía vínculo à época da publicação do artigo. Ao todo, conforme quadro 2, os artigos analisados são originários de 32 diferentes instituições. Em virtude das coautorias, salienta-se que um mesmo artigo pode ter sido classificado em duas ou mais instituições de origem. Logo, o quadro 2 representa a frequência de artigos que apresentaram autores vinculados a cada instituição e não o número total de artigos analisados.

Quadro 2

Frequência dos artigos vinculados às instituições

\begin{tabular}{|lc|}
\hline \multicolumn{1}{|c|}{ Instituiçães de origem dos artigos } & № de artigos \\
\hline Escola de Administração de Empresas de São Paulo/Fundação Getulio Vargas (EAESP/FGV) & 7 \\
Universidade de São Paulo (USP) & 5 \\
Universidade de Brasília (UnB) & 5 \\
Universidade Federal de Pernambuco (UFPE) & 5 \\
Pontifícia Universidade Católica (PUC) & 4 \\
Universidade Federal de Minas Gerais (UFMG) & 3 \\
Universidade Federal da Bahia (UFBA) & 3 \\
Escola Brasileira de Administração Pública e de Empresas/Fundação Getulio Vargas (EBAPE/FGV) & 2 \\
University of Cambridge & 2 \\
Universidade do Minho & 1 \\
\hline
\end{tabular}

\footnotetext{
${ }^{6}$ São elas a Revista Brasileira de Ciências Sociais (RBCS), a Revista de Sociologia e Política (Sol\&Pol) e a revista Lua Nova.
} 


\begin{tabular}{|c|c|}
\hline Instituições de origem dos artigos & № de artigos \\
\hline Universidade de Ottawa & 1 \\
\hline Universidade de Nova York e Universidade de Yale & 1 \\
\hline University of Notre Dame & 1 \\
\hline Université de Montréal & 1 \\
\hline Universidad de Chile & 1 \\
\hline Universidade Estadual de Campinas (Unicamp) & 1 \\
\hline Universidade Federal do Rio de Janeiro (UFRJ) & 1 \\
\hline Universidade Federal do Rio Grande do Sul (UFRGS) & 1 \\
\hline Universidade Federal do Paraná (UFPR) & 1 \\
\hline Universidade Federal de São Carlos (Ufscar) & 1 \\
\hline Universidade Estadual de Londrina (UEL) & 1 \\
\hline Princeton University & 1 \\
\hline University of Oxford & 1 \\
\hline New School for Social Research & 1 \\
\hline MCM Consultores Associados & 1 \\
\hline Instituto Universitário de Pesquisas do Rio de Janeiro (luferj) & 1 \\
\hline Institut d'Études Politiques Paris & 1 \\
\hline Instituto Brasileiro de Mercados de Capitais (Ibmec) & 1 \\
\hline Fundação Escola de Comércio Álvares Penteado (Fecap) & 1 \\
\hline Escola de Magistratura de Pernambuco & 1 \\
\hline Centro Brasileiro de Análise e Planejamento (Cebrap) & 1 \\
\hline Augurium Consultoria & 1 \\
\hline
\end{tabular}

Fonte: Dados da pesquisa (2011).

Do total de instituições, EAESP/FGV, Iuperj, PUC, UFBA, UFMG, UFPE, UnB e USP aparecem citadas em ao menos três artigos. A centralidade de universidades brasileiras, e públicas, pode se dar pelo fato de as revistas pesquisadas neste estudo serem brasileiras. Mesmo tendo reconhecimento global, o fato de serem revistas em língua portuguesa favorece o maior aparecimento de artigos nacionais, não podendo caracterizar uma centralidade do país no tema, apesar de algumas das instituições citadas serem centros de pesquisa internacionalmente reconhecidos.

Conforme mencionado nos procedimentos metodológicos, foram escolhidos artigos de três áreas de avaliação listadas na Capes. O termo accountability apresentou a seguinte frequência nestas revistas: 
Figura 3

Número de artigos por periódicos

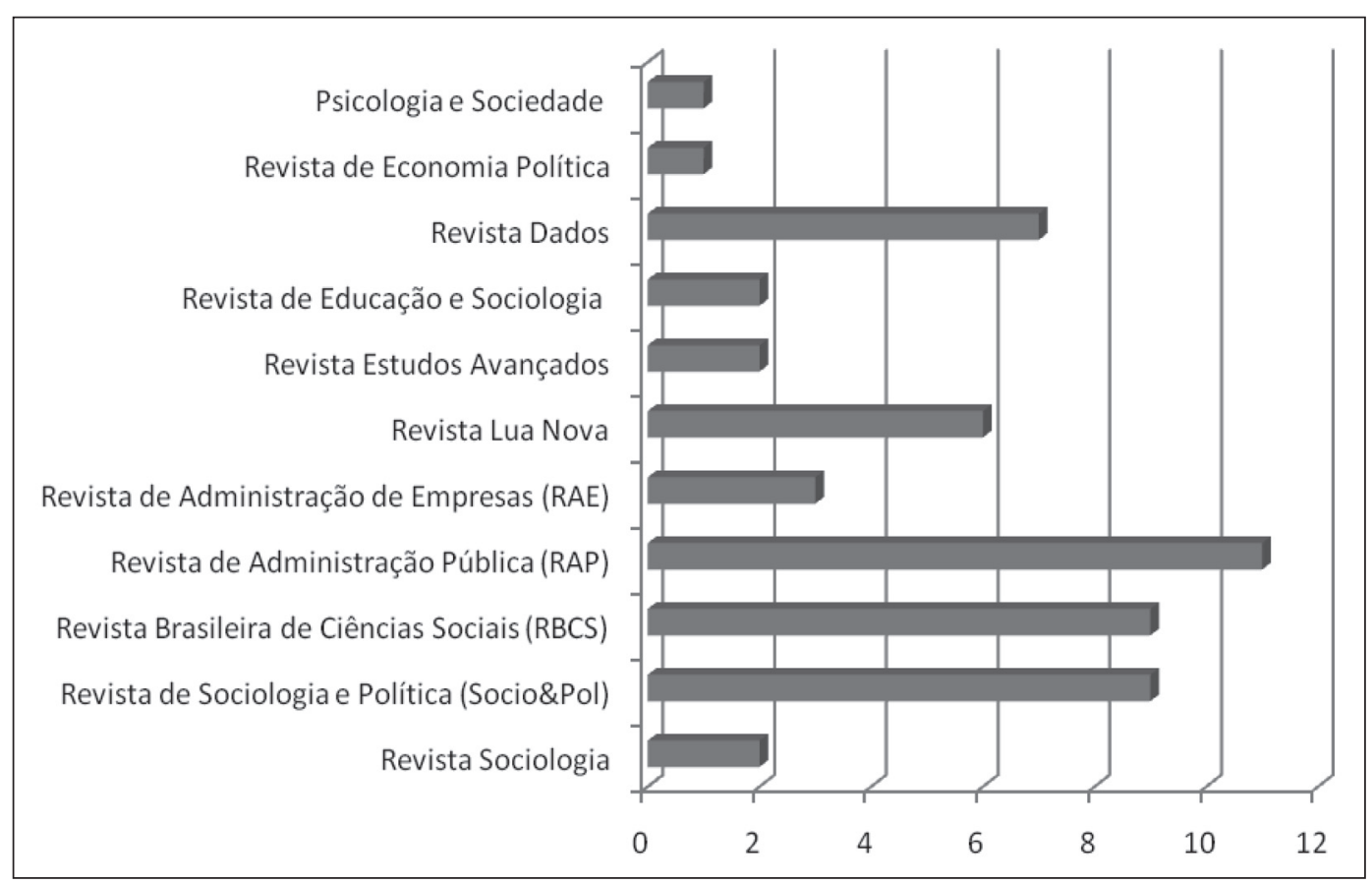

Fonte: Dados da pesquisa (2011).

Assim, é possível perceber que o tema abrange grande representação nas três áreas de avaliação listadas pela Capes. Tanto revistas de administração, quanto aquelas de ciência política e ciências sociais aplicadas apresentam considerável número de artigos que tratam do tema accountability. RAP, RBCS e Socio\&Pol somam 30 artigos. Mesmo revistas que não têm temas diretamente relacionados à accountability, como Edu\&Soc, mais voltada para debates acerca de educação, acabam trazendo artigos que trabalham o conceito de accountability.

Sobre o conceito de accountability, por sua vez, vale a consideração de que muitos artigos não o definem ou exploram conceitualmente, apenas utilizam seu conceito para desenvolver objetivos diversos. Da mesma forma, menos da metade (38\%) dos artigos trata de estudos teóricos sobre accountability, ou temas correlatos, sendo a maior parte (62\%) estudos empíricos. Esta divisão da natureza dos estudos analisados foi elaborada a partir da leitura e análise de cada texto, dado que nem todos traziam explicitamente esta informação.

Inicialmente, a divisão considerava ainda a variável "teórico/empírico", para aqueles artigos que, apesar de se debruçar em questões empíricas, apresentavam uma breve contextualização teórica. Após uma reflexão aprofundada sobre o método, uma vez que a variável mútua tornava os critérios menos precisos, optou-se por definir a divisão de natureza dos estudos pelo fator mais marcante: se voltado para o debate teórico sobre o tema, ou se voltado para o estudo de casos, mesmo que embasado teoricamente. 
Figura 4

Número de artigos por método de análise

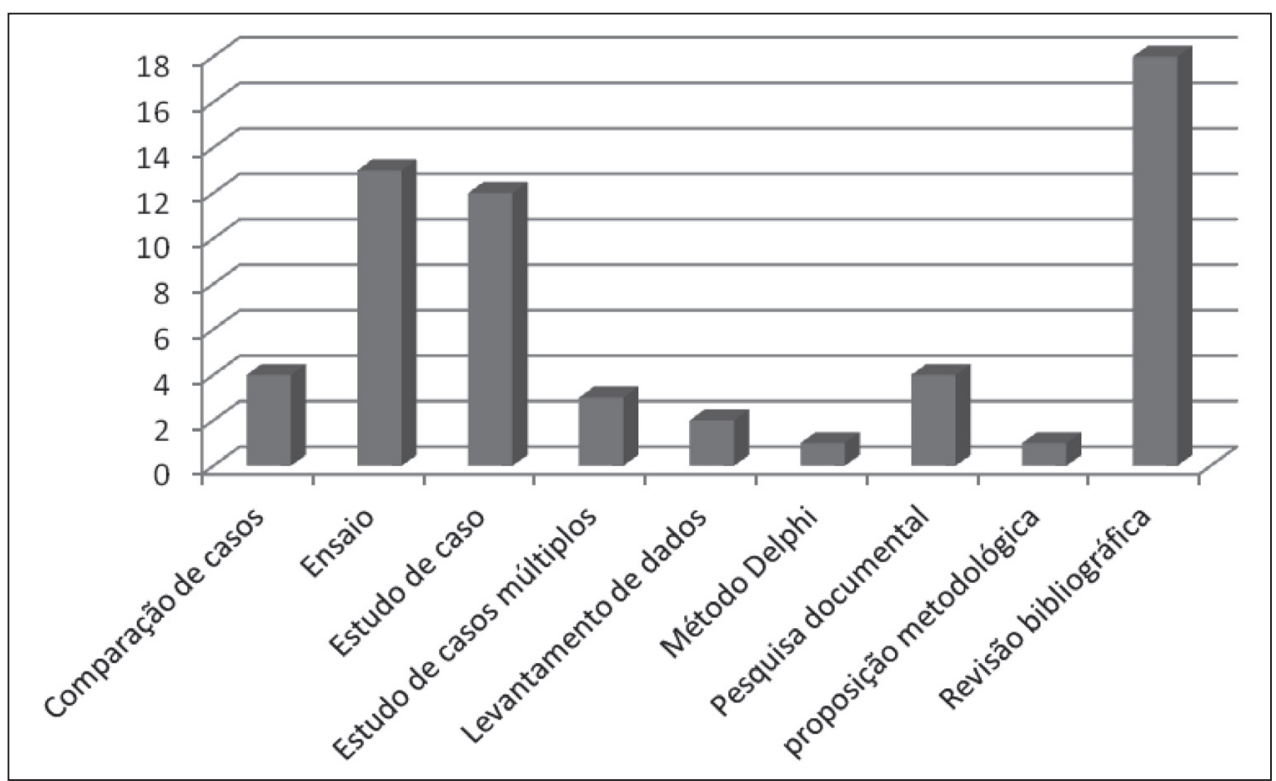

Fonte: Dados da pesquisa (2011).

Também foram analisados os métodos utilizados por autor, com alguns artigos empregando a combinação de diferentes métodos para atingir seus objetivos. Os mais utilizados pelos artigos foram: comparação de casos; ensaio; estudo de caso; estudo de casos múltiplos; levantamento de dados; método Delphi; pesquisa documental; proposição metodológica e revisão bibliográfica.

Conforme a figura 4, é possível perceber que ensaios, estudos de caso e revisões bibliográficas são os métodos mais comumente utilizados pelos autores. São ainda os métodos mais comumente combinados nas propostas dos artigos analisados.

\subsection{Conceitos, experiências analisadas e abordagens sobre accountability}

Esta seção tem por objetivo identificar e analisar como o tema accountability está sendo tratado na literatura brasileira. Para tanto, os artigos foram classificados em três categorias: (1) artigos que não tratam do tema accountability; (2) artigos que discutem a accountability entre outros temas pesquisados; e (3) artigos que discutem a accountability como tema principal.

Conforme a figura 5, percebe-se que a maioria dos artigos pesquisados (33) trata o tema accountability em suas discussões. Não obstante, 20 artigos, apesar de conterem a palavra ac- 
countability em sua redação ou mesmo no abstract como tradução para o inglês, não abordam o tema em si, sendo este apenas mencionado em algum contexto específico.

Figura 5

Número de artigos por tratamento dado ao tema accountability

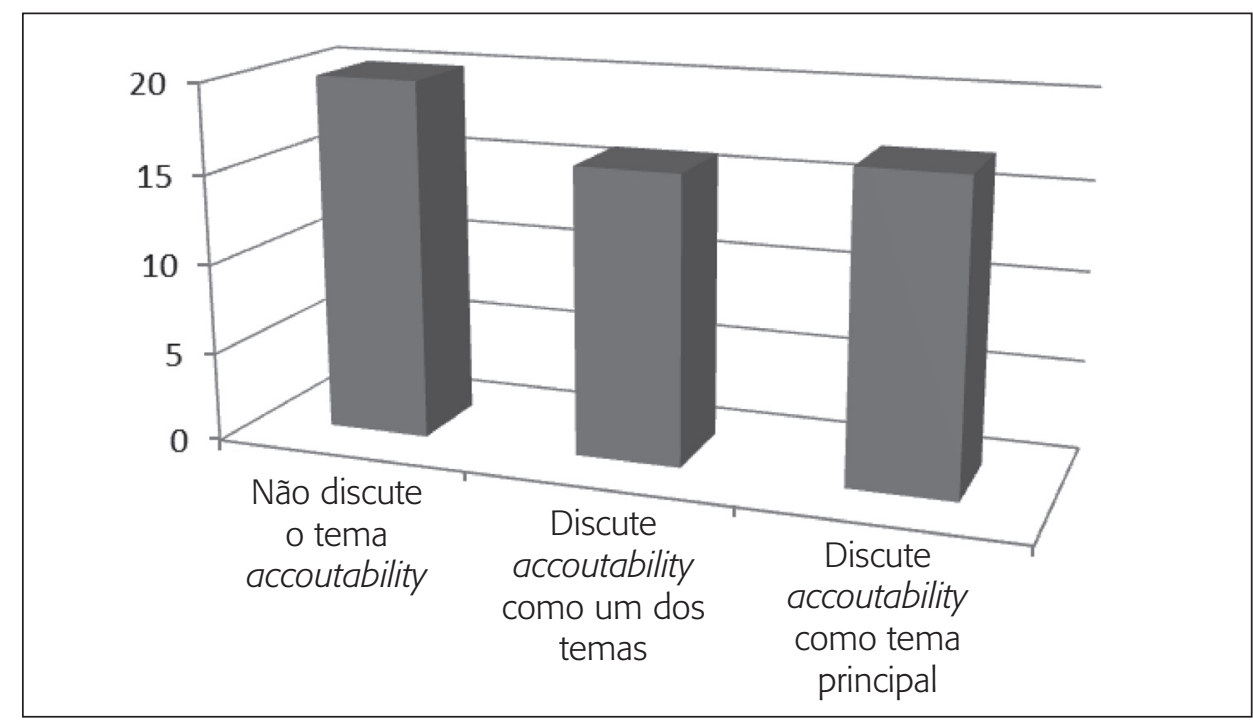

Fonte: Dados da pesquisa (2011).

Analisando as discussões dos artigos, constatou-se, conforme a figura 6, que 13 não apresentaram experiências (casos) para evidenciar o tema, tratando-se, portanto, de artigos teóricos. Os artigos que apresentaram alguma experiência totalizaram 40. Porém, apenas 23 destes focaram experiências que evidenciavam a prática de accountability, destacando como esta ocorre ou sua presença ou ausência em determinadas instituições.

Salienta-se que o fato de terem sido identificados artigos que não tratam do tema, mesmo apresentando a palavra em sua redação, pode ser justificado por terem sido analisados não só periódicos da área pública ou de ciência política (onde são mais prováveis as publicações sobre accountability), mas também artigos das áreas de administração e ciências sociais, conforme já evidenciado.

Entre os artigos que apresentam experiências relacionadas à accountability (figura 7), constatou-se que, em 12 casos, a accountability foi tratada como o eixo principal do artigo e, em 11, como um dos temas. Por outro lado, os artigos que apenas citaram a palavra accountability, como era o esperado, não analisaram experiências relacionadas ao tema. 
Figura 6

Número de artigos conforme as experiências analisadas

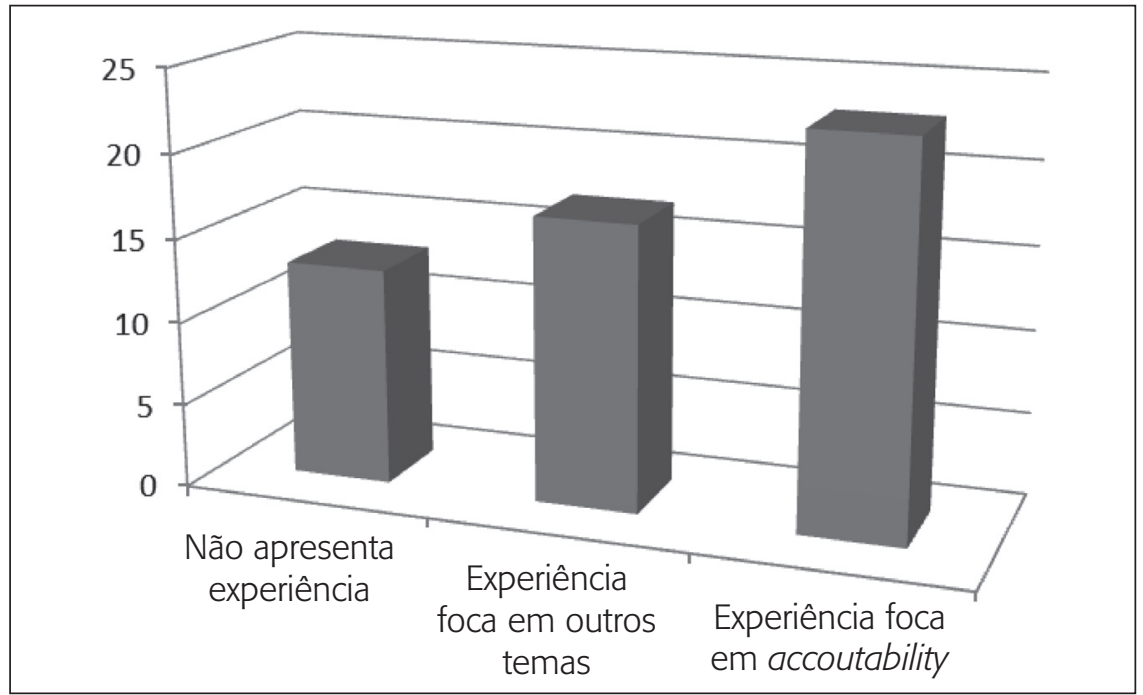

Fonte: Dados da pesquisa (2011).

Figura 7

Número de artigos conforme experiências analisadas

e tratamento dado ao tema

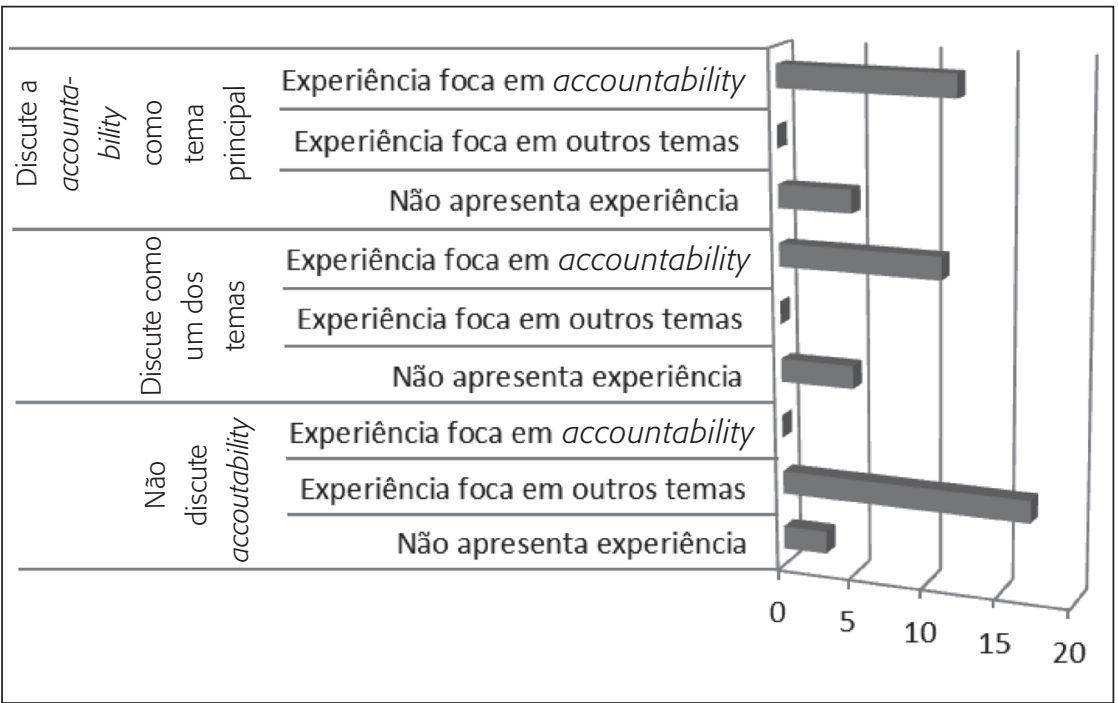

Fonte: Dados da pesquisa (2011) 
Entre as experiências que analisam a accountability, apresentadas no quadro 3, destacase o caso das agências reguladoras, estudadas em três artigos, e o caso do Banco Central do Brasil, estudado em dois artigos. As demais experiências analisadas nos artigos apresentaramse de maneira isolada.

Quadro 3

Objetos de pesquisa nos quais a accountability foi analisada

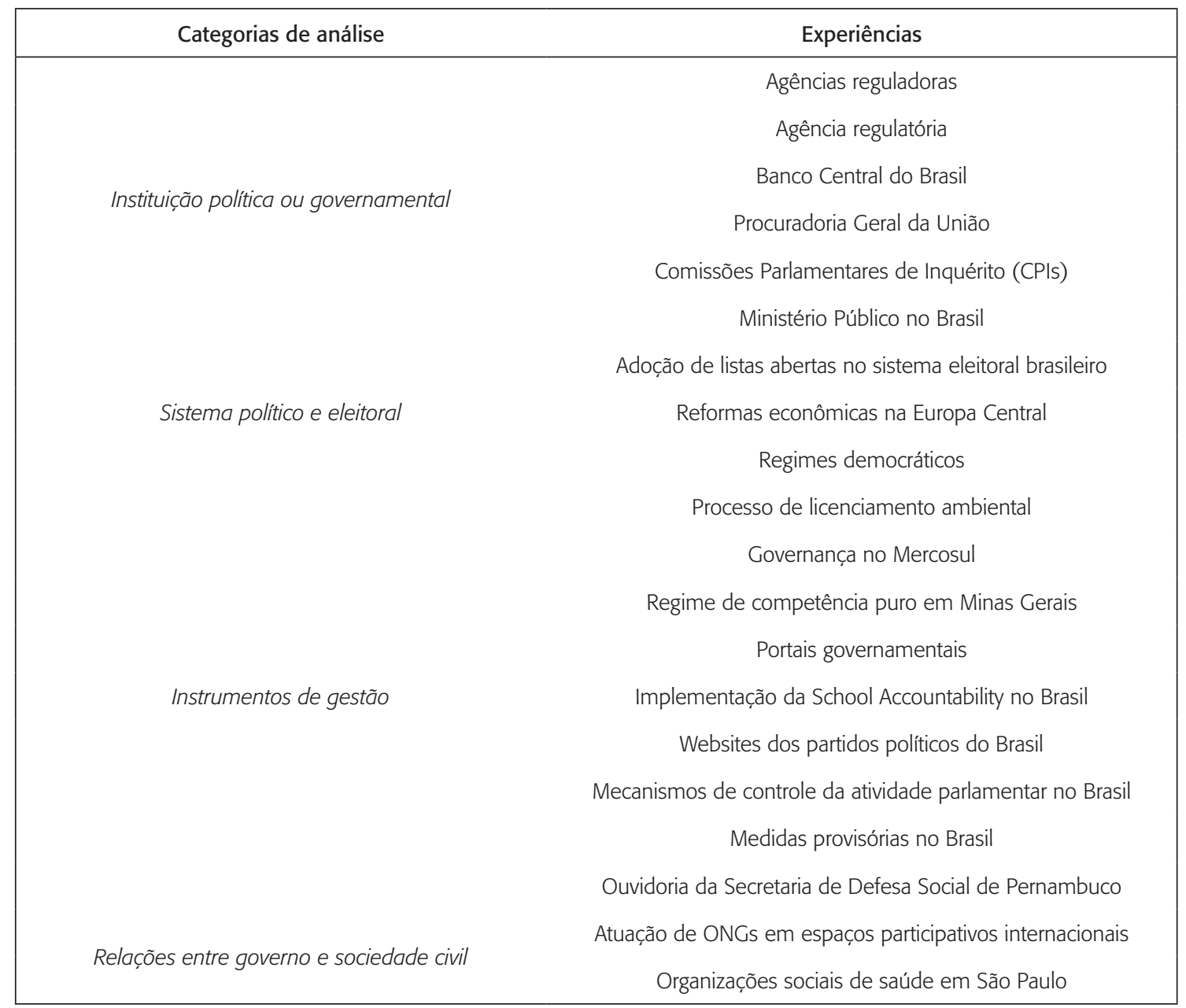

Fonte: Dados da pesquisa (2011).

Os instrumentos de gestão pública são as experiências mais analisadas nos artigos pesquisados (13), seguidos das experiências relacionadas às instituições políticas ou governamentais (sete), ao sistema político e eleitoral (três) e às relações entre governo e sociedade civil (dois). 
Denota-se a importância da identificação e análise dessas experiências para ilustrar o que os estudos têm considerado como prática ou instrumento de accountability, e para evidenciar os objetos mais e menos estudados.

Analisando os principais elementos presentes nos conceitos de accountability apresentados nos artigos, conforme o quadro 4, observou-se que o termo "responsabilização" foi o mais citado, aparecendo em 20 artigos. O termo "prestação de contas" foi o segundo mais citado, totalizando 16 artigos, seguido dos termos "transparência" (sete); "sanções" (cinco); "controle político" (quatro), "responsabilidade" (quatro), "responsividade" (três) e "responsabilidade política", "controle eleitoral"; "supervisão" e "ações das agências de controle" (dois artigos referentes a cada termo).

\section{Quadro 4}

Elementos considerados nos conceitos de accountability de acordo com o tratamento dado ao tema

\begin{tabular}{|ccccc|}
\hline Elementos considerados no conceito & $\begin{array}{c}\text { Não discute } \\
\text { accountability }\end{array}$ & $\begin{array}{c}\text { Discute como um } \\
\text { dos temas }\end{array}$ & $\begin{array}{c}\text { Dccountability como } \\
\text { tema principal }\end{array}$ & Total \\
\hline Responsabilização & 2 & 10 & 8 & 20 \\
Prestação de contas & 3 & 4 & 9 & 16 \\
Não traduz e nem define & 9 & 1 & 3 & 13 \\
Transparência & 2 & 2 & 3 & 7 \\
Sanções & 0 & 2 & 3 & 5 \\
Controle político & 1 & 0 & 3 & 4 \\
Responsabilidade & 0 & 1 & 3 & 4 \\
Responsividade & 1 & 1 & 1 & 3 \\
Responsabilidade Política & 0 & 2 & 0 & 2 \\
Controle eleitoral & 1 & 0 & 1 & 2 \\
Supervisão & 0 & 0 & 2 & 2 \\
Ações das agências de controle & 0 & 0 & 2 & 1 \\
Controle social & 1 & 0 & 0 & 1 \\
Controle & 0 & 0 & 1 & 1 \\
Delegação & 0 & 0 & 1 & 1 \\
Avaliação retrospectiva & 0 & 0 & 0 & 1 \\
Informação & 0 & 0 & 1 & 1 \\
Justificação & 0 & 0 & 1 & 1 \\
Legitimidade & 1 & 0 & 1 \\
Punição & 0 & 0 & 1 & 2 \\
\hline
\end{tabular}

Fonte: Dados da pesquisa (2011). 
Os demais elementos identificados e apresentados no quadro 4 foram citados de forma específica em cada artigo. Ressalta-se que 13 artigos não definem nem traduzem o termo $a c$ countability, sendo apenas citado em algum contexto específico.

Os dados apresentados demonstram certa "confusão" quanto ao uso do termo accountability. Embora este ainda não possa ser traduzido do inglês para o português, e verifica-se que há interpretações diferentes sobre seu significado, pode-se afirmar que sua conceituação, por vezes, é equivocada (palavras com significação diferente sendo consideradas sinônimas) ou incompleta (a palavra por si só não explica o significado da accountability, nem sua complexidade).

Apesar dessa variedade de termos, pode-se afirmar que, na literatura brasileira, a accountability ainda está relacionada principalmente às ideias de responsabilidade e prestação de contas.

Analisando os tipos de accountability apresentados pelos autores (quadro 5), os quais neste estudo foram considerados abordagens, constatou-se que os mais citados foram a "accountability vertical" (15 artigos) e a "accountability horizontal" (16 artigos), ambos apresentados por O’Donnell (1998). Segundo este autor e conforme já evidenciado, a accountability vertical se refere à necessidade que os representantes (detentores de mandatos) têm de prestar contas e submeter-se ao veredicto da população. Esse tipo de accountability tem nas eleições seu principal instrumento, utilizando de mecanismos tradicionais de premiação e punição. Já a accountability horizontal se refere à capacidade que poderes estatais têm de supervisionar as ações uns dos outros. Tal supervisão envolve desde a supervisão de rotina como sanções legais ou até o impeachment contra ações consideradas delituosas (O'Donnell, 1998).

A accountability política e a accountability social, segundo definição de Peruzzotti e Smulovitz (2001), também foram citadas em dois artigos. Embora a definição de accountability política tenha sido apresentada nos artigos sem o suporte de algum autor específico, podese depreender que seu significado corrobora a definição de accountability vertical apresentada por O'Donnell. Logo, pode-se afirmar que estas duas abordagens são convergentes, embora recebam nomenclaturas diferentes.

No que se refere à accountability social, também apresentada por Peruzzotti e Smulovitz (2001), os autores afirmam que ela se refere à accountability exercida pelos meios de comunicação e por organizações não governamentais (ONGs). Embora esse tipo de accountability não permita a aplicação de sanções, esta, indiretamente, pode acabar exercendo alguma punição, visto que suas advertências e denúncias ganham efetividade quando um dos poderes constituídos, em especial o Judiciário (accountability horizontal) ou o eleitorado (accountability vertical) é sensibilizado.

A responsabilidade política ${ }^{7}$ estendida, conforme definição de Stark e Bruszt (1998:26), corresponde à "imbricação dos centros de tomada de decisões em redes de instituições políticas autônomas que limitam a arbitrariedade dos governantes no poder". Segundo os referidos autores, esse tipo de accountability se estende "horizontalmente" durante todo o mandato e não apenas no processo eleitoral. Embora o conceito de responsabilidade política estendida apresente clara semelhança com o conceito de accountability horizontal de O’Donnel (1998),

\footnotetext{
${ }^{7}$ Stark e Bruszt (1998) traduzem a palavra accountability como responsabilidade política.
} 
o primeiro avança no sentido de considerar a responsabilidade política não só entre instituições internas do Estado, mas também inclui outras instituições políticas, especialmente os outros agentes organizados da sociedade (Stark e Bruszt, 1998).

Salienta-se que os demais tipos de accountability identificados foram citados de forma isolada em cada artigo.

Analisando somente os artigos que trataram do tema accountability em suas discussões, constatou-se que as abordagens mais citadas também foram a accountability horizontal e a accountability vertical apresentadas por O’Donnell (quadro 5).

\section{Quadro 5 \\ Abordagens (tipologias) sobre accountability em comparação com o tratamento dado ao tema nos artigos}

\begin{tabular}{|c|c|c|c|c|}
\hline Abordagens (tipologias) e autores & $\begin{array}{l}\text { Não discute } \\
\text { accountability }\end{array}$ & $\begin{array}{c}\text { Discute } \\
\text { como um } \\
\text { dos temas }\end{array}$ & $\begin{array}{c}\text { Discute a } \\
\text { accountability como } \\
\text { tema principal }\end{array}$ & Total \\
\hline Não apresenta tipologias & 16 & 6 & 4 & 26 \\
\hline Accountability horizontal (O'Donnell, 1991, 1998) & 3 & 5 & 8 & 16 \\
\hline Accountability vertical (O'Donnell, 1991, 1998) & 2 & 3 & 10 & 15 \\
\hline Accountability horizontal & 1 & 0 & 3 & 4 \\
\hline Accountability vertical & 1 & 0 & 3 & 4 \\
\hline Accountability eleitoral & 0 & 1 & 2 & 3 \\
\hline Accountability social (Peruzzotti e Smulovitz, 2001) & 0 & 0 & 2 & 2 \\
\hline Responsabilidade política estendida I (Stark e Bruszt, 1998) & 0 & 1 & 1 & 2 \\
\hline Delegacão e representacão (Grant e Keohane, 2005) & 0 & 1 & 0 & 1 \\
\hline Accountability eleitoral (Powell, 2000) & 0 & 1 & 0 & 1 \\
\hline Accountability view (Pitkin, apud Melo, 2007) & 0 & 1 & 0 & 1 \\
\hline Accountability política & 0 & 1 & 0 & 1 \\
\hline Accountability administrativa & 0 & 1 & 0 & 1 \\
\hline Accountability de desempenho & 0 & 1 & 0 & 1 \\
\hline Accountability procedimental & 0 & 1 & 0 & 1 \\
\hline $\begin{array}{l}\text { Accountability vertical (Shugart, Moreno e Crisp, apud } \\
\text { Maria, 2010) }\end{array}$ & 0 & 0 & 1 & 1 \\
\hline Accountability governamental & 0 & 1 & 0 & 1 \\
\hline Responsabilização dos governantes e políticos pelos cidadãos & 0 & 1 & 0 & 1 \\
\hline Responsabilização dos burocratas & 0 & 1 & 0 & 1 \\
\hline Accountability legal & 0 & 0 & 1 & 1 \\
\hline Accountability pura & 0 & 0 & 1 & 1 \\
\hline Accountability model (Powel, 2000) & 0 & 0 & 1 & 1 \\
\hline Accountability das burocracias (Dahl, 1971) & 1 & 0 & 0 & 1 \\
\hline
\end{tabular}

Fonte: Dados da pesquisa (2011). 
Após analisar como o tema accountability está sendo tratado na literatura brasileira, bem como sua abrangência e as abordagens principais, percebe-se a dificuldade dos autores em conseguir conceituar este termo, conforme já mencionado, bem como de apontar formas de ocorrência diferentes daquelas já consolidadas (como a tipologia de O'Donnell). Dessa forma, embora este trabalho tenha identificado diferentes tipos de accountability, classificados em diferentes tipologias, estes, em sua maioria, abordam os mesmos elementos.

\subsection{Panorama geral: o uso do termo accountability nos estudos brasileiros}

Com base nas análises da seção anterior, propõe-se uma sistematização sobre o uso do termo accountability na literatura brasileira. Ressalta-se que, para tanto, tomou-se como ponto de partida o quadro "Accountability democrática", elaborado pelos autores Abrucio e Loureiro (2004:81-82), apresentado no marco teórico deste estudo (quadro 1). A utilização deste quadro como base para a análise deveu-se ao fato de o mesmo já representar um esforço de sistematização dos tipos de accountability existentes em regimes democráticos, sobretudo na contemporaneidade, e, ainda, por contemplar, em essência, a maioria dos mecanismos de accountability presentes nas demais classificações encontradas na literatura sobre o tema.

Dessa forma, acredita-se que a ampliação desta sistematização corrobora as formas de accountability já evidenciadas, e apresenta novas tipologias e elementos criados ao longo da evolução dos estudos.

Salienta-se que, apesar de tomar o quadro de Abrucio e Loureiro (2004:81-82) como base para a apresentação do panorama geral dos estudos em accountability no Brasil, algumas adaptações foram necessárias para a melhor apresentação e compreensão dos dados coletados.

Dessa forma, foram incluídas as colunas "Formas de Ocorrência", ou seja, sob que escopo ou especificação estes modelos podem acontecer; "Momentos de Ocorrência"; e "Fórum", ou seja, qual(is) ator(es) inicia(m) a prática de accountability. Após a inclusão destas características, também foram acrescidas novas linhas para cada novo tipo identificado na literatura brasileira. Em dados momentos, as abordagens identificadas neste estudo foram agrupadas nas colunas "Tipos de Accountability" ou "Formas de Ocorrência", por serem consideradas convergentes, e, portanto, passíveis de serem agrupadas numa mesma categoria. A seguir apresenta-se o panorama geral (quadro 6). 


\section{Quadro 6}

Sistematização do uso do termo accountability

\begin{tabular}{|c|c|c|c|c|}
\hline Tipo de accountability & Formas de ocorrência & $\begin{array}{l}\text { Momento de } \\
\text { ocorrência }\end{array}$ & Instrumentos & $\begin{array}{l}\text { Quem exerce? } \\
\text { (Fórum) }\end{array}$ \\
\hline \multirow[t]{6}{*}{$\begin{array}{l}\text { Accountability vertical } \\
\text { (O'Donnell, 1998) } \\
\text { ou } \\
\text { Accountability política } \\
\text { (Arato, 2002; Bevir, } \\
2011 \text { ) }\end{array}$} & $\begin{array}{l}\text { Processo eleitoral } \\
\text { (accountability eleitoral; } \\
\text { Powell Jr. (2000); } \\
\text { accountability por delegação; } \\
\text { Grant e Keohane (2005); } \\
\text { accountability model; Powell } \\
\text { Jr. (2000) }\end{array}$ & Período de eleição & $\begin{array}{l}\text { Eleições regulares } \\
\text { para os postos de } \\
\text { Executivo e Legislativo }\end{array}$ & Cidadãos \\
\hline & \multirow{2}{*}{$\begin{array}{l}\text { Democracia direta } \\
\text { (accountability por } \\
\text { Participação; Grant e } \\
\text { Keohane (2005) }\end{array}$} & Durante o mandato & Plebiscitos & Cidadãos \\
\hline & & $\begin{array}{l}\text { Após a edição de } \\
\text { algum ato legislativo } \\
\text { ou administrativo sobre } \\
\text { determinados assuntos } \\
\text { de relevante interesse } \\
\text { à nação }\end{array}$ & Referendos & Cidadãos \\
\hline & \multirow[t]{3}{*}{$\begin{array}{l}\text { Gestão participativa } \\
\text { (accountability por } \\
\text { Participação; Grant e } \\
\text { Keohane (2005) }\end{array}$} & $\begin{array}{l}\text { Durante o mandato } \\
\text { (deliberação conjunta } \\
\text { com representantes } \\
\text { governamentais) }\end{array}$ & $\begin{array}{l}\text { Conferências setoriais } \\
\text { de políticas públicas }\end{array}$ & Cidadãos \\
\hline & & $\begin{array}{l}\text { Durante o mandato } \\
\text { (deliberação conjunta } \\
\text { com representantes } \\
\text { governamentais) }\end{array}$ & $\begin{array}{l}\text { Conselhos de Políticas } \\
\text { Públicas }\end{array}$ & Cidadãos \\
\hline & & $\begin{array}{l}\text { Durante o mandato } \\
\text { (deliberação conjunta } \\
\text { com representantes } \\
\text { governamentais) }\end{array}$ & $\begin{array}{l}\text { Orçamentos } \\
\text { Participativos (OPs) }\end{array}$ & Cidadãos \\
\hline \multirow[t]{2}{*}{$\begin{array}{l}\text { Accountability } \\
\text { horizontal (O'Donnell, } \\
\text { 1998) }\end{array}$} & $\begin{array}{l}\text { Controle parlamentar } \\
\text { (controles mútuos) }\end{array}$ & Permanente & $\begin{array}{l}\text { CPI, arguição e } \\
\text { aprovação de } \\
\text { altos dirigentes } \\
\text { públicos, fiscalização } \\
\text { orçamentária e } \\
\text { de desempenho } \\
\text { das agências } \\
\text { governamentais, } \\
\text { audiências públicas }\end{array}$ & Parlamentares \\
\hline & Controle judicial & Permanente & $\begin{array}{l}\text { Controle da } \\
\text { constitucionalidade, } \\
\text { ações civis públicas, } \\
\text { garantia dos direitos } \\
\text { fundamentais etc. }\end{array}$ & Parlamentares \\
\hline
\end{tabular}




\begin{tabular}{|c|c|c|c|c|}
\hline Tipo de accountability & Formas de ocorrência & $\begin{array}{l}\text { Momento de } \\
\text { ocorrência }\end{array}$ & Instrumentos & $\begin{array}{l}\text { Quem exerce? } \\
\text { (Fórum) }\end{array}$ \\
\hline & $\begin{array}{l}\text { Controle administrativo- } \\
\text { procedimental } \\
\text { (accountability } \\
\text { Procedimental; Da Ros } \\
\text { (2008) }\end{array}$ & Permanente & $\begin{array}{l}\text { Tribunal de Contas e/ } \\
\text { ou auditoria financeira }\end{array}$ & Burocracia pública \\
\hline & $\begin{array}{l}\text { Accountability administrativa; } \\
\text { (accountability das } \\
\text { burocracias; Dahl (1971) }\end{array}$ & Permanente & $\begin{array}{l}\text { Regras internas } \\
\text { de cada órgão } \\
\text { governamental }\end{array}$ & Burocracia pública \\
\hline & $\begin{array}{l}\text { Controle do desempenho } \\
\text { dos programas } \\
\text { governamentais } \\
\text { (accountability de } \\
\text { desempenho; Da Ros } \\
\text { (2008) }\end{array}$ & Permanente & $\begin{array}{l}\text { Metas e objetivos } \\
\text { compactualizados } \\
\text { no início de } \\
\text { cada programa } \\
\text { governamental. }\end{array}$ & Burocracia pública \\
\hline & $\begin{array}{l}\text { Regras estatais } \\
\text { intertemporais } \\
\text { (accountability legal; Arato } \\
(2002)\end{array}$ & Permanente & $\begin{array}{l}\text { Garantias de } \\
\text { direitos básicos } \\
\text { pela Constituição } \\
\text { (cláusulas pétreas); } \\
\text { segurança contratual } \\
\text { individual e coletiva; } \\
\text { limitação legal } \\
\text { do poder dos } \\
\text { administradores } \\
\text { públicos; acesso } \\
\text { prioritário aos cargos } \\
\text { administrativos } \\
\text { por concursos } \\
\text { ou equivalentes; } \\
\text { mecanismos de } \\
\text { restrição orçamentária; } \\
\text { defesa de direitos } \\
\text { intergeracionais }\end{array}$ & Parlamentares \\
\hline $\begin{array}{l}\text { Responsabilidade } \\
\text { política estendida } \\
\text { (Stark e Bruszt, 1998) }\end{array}$ & $\begin{array}{l}\text { Imbricação dos centros } \\
\text { de tomada de decisões } \\
\text { em redes de instituições } \\
\text { políticas autônomas que } \\
\text { limitam a arbitrariedade dos } \\
\text { governantes no poder }\end{array}$ & Permanente & $\begin{array}{l}\text { Redes de } \\
\text { responsabilidade entre } \\
\text { instituições do Estado } \\
\text { e agentes organizados } \\
\text { da sociedade }\end{array}$ & $\begin{array}{l}\text { Instituições } \\
\text { internas do Estado } \\
\text { e outros agentes } \\
\text { organizados da } \\
\text { sociedade }\end{array}$ \\
\hline
\end{tabular}




\begin{tabular}{|c|c|c|c|c|}
\hline Tipo de accountability & Formas de ocorrência & $\begin{array}{l}\text { Momento de } \\
\text { ocorrência }\end{array}$ & Instrumentos & $\begin{array}{l}\text { Quem exerce? } \\
\text { (Fórum) }\end{array}$ \\
\hline $\begin{array}{l}\text { Accountability pura } \\
\text { (Arato, 2002) }\end{array}$ & $\begin{array}{l}\text { Modelo ideal, onde os } \\
\text { cidadãos têm controle sobre } \\
\text { as atividades parlamentares; } \\
\text { baseado em uma única } \\
\text { câmara legislativa; } \\
\text { incompatível com governos } \\
\text { de coalização; com prazos } \\
\text { eleitorais curtos }\end{array}$ & Período de eleição & $\begin{array}{l}\text { Eleições regulares e } \\
\text { em períodos curtos } \\
\text { para os postos do } \\
\text { Legislativo }\end{array}$ & $\begin{array}{l}\text { Cidadãos sobre } \\
\text { parlamentares }\end{array}$ \\
\hline \multirow[t]{3}{*}{$\begin{array}{l}\text { Accountability } \\
\text { social (Peruzzotti e } \\
\text { Smulovitz, 2001) }\end{array}$} & $\begin{array}{l}\text { Associativismo civil (os } \\
\text { atores são guiados por } \\
\text { uma visão sistêmica que } \\
\text { procura gerar respostas } \\
\text { para problemas que são } \\
\text { percebidos como estruturais } \\
\text { ou de longa data) }\end{array}$ & Permanente & $\begin{array}{l}\text { Supervisão do } \\
\text { comportamento } \\
\text { de funcionários ou } \\
\text { agências públicas }\end{array}$ & $\begin{array}{l}\text { Associações civis e } \\
\text { ONGs }\end{array}$ \\
\hline & $\begin{array}{l}\text { Movimentos sociais (os } \\
\text { atores estão organizados } \\
\text { em torno de uma demanda } \\
\text { concreta e particular, ou seja, } \\
\text { representam reações de } \\
\text { setores sociais) }\end{array}$ & Permanente & $\begin{array}{l}\text { Mobilização social; } \\
\text { pressão sobre as } \\
\text { agências de controle } \\
\text { correspondentes } \\
\text { para que ativem } \\
\text { os mecanismos de } \\
\text { investigação e sanção }\end{array}$ & $\begin{array}{l}\text { Movimentos } \\
\text { sociais conjunturais } \\
\text { de setores sociais }\end{array}$ \\
\hline & Jornalismo de denúncia & Permanente & $\begin{array}{l}\text { Denúncia e exposição } \\
\text { de casos de violação } \\
\text { da lei ou de corrupção } \\
\text { por parte das } \\
\text { autoridades }\end{array}$ & Mídia \\
\hline
\end{tabular}

Fonte: Elaborado pelas autoras a partir de Abrucio e Loureiro (2004) e dos dados coletados neste estudo (2011).

O quadro 6 traz a sistematização do uso do termo accountability e avança no sentido de ampliar os significados a ele atribuídos. Além da já citada definição entre accountability vertical e horizontal (O’Donnel, 1991; 1998), há ainda a definição que aproxima a accountability vertical da accountability política (Arato, 2002; Bevir, 2011) e aquela que aproxima a accountability horizontal da accountability governamental (Olivieri, 2007). Contudo, são três as tipologias que fogem à definição de O'Donnel, apesar de guardar semelhanças: a definição como responsabilidade política estendida (Stark e Bruszt, 1998); a definição como accountabilty pura (Arato, 2002); e, por fim, a definição como accountability social (Peruzzotti e Smulovitz, 2001). 


\section{Considerações finais}

Quando se imaginou a proposta deste estudo, a expectativa das autoras foi encontrar uma série de artigos e, sobretudo, diferentes usos para o termo accountability. Porém, apenas 53 artigos foram encontrados em toda a base pesquisada, número considerado baixo perante a maciça produção acadêmica brasileira nos campos pesquisados. Uma pesquisa mais abrangente em outras categorias de avaliação da Capes, na tentativa de ampliar a amostra, se relevou ineficiente, já que poucos resultados foram encontrados, não justificando modificar a metodologia proposta. Destes 53 artigos encontrados, 13 não definem o termo accountability, o que tornou o resultado ainda mais surpreendente, pois o número total de artigos não se mostra tão abrangente a ponto de dispensar a explicação do conceito, sobretudo tratando-se de um termo em outra língua.

Por outro lado, a falta de definição do termo, em contraponto a seu uso aplicado empiricamente, pode apontar para uma capilarização deste, que pode ter sido apropriado pela academia, ${ }^{8}$ e vem sendo usado mais frequentemente.

É importante pontuar que, após a redemocratização brasileira, tendo como marco a Constituição Federal de 1988, expressões como democracia, participação popular, controle social e a própria accountability passaram a figurar como "jargões" que legitimam ações públicas, mesmo que essas orientações não sejam aplicadas na prática. Como são conceitos ainda em construção, é relativamente simples se apropriar dos termos para diferentes formas de ação. Fonseca (2011:11) explica:

Conceitos e critérios como empoderamento, participação, capital social, accountability (responsabilização), descentralização, educação de qualidade, combate à corrupção, eficiência dos mercados, mão de obra qualificada, igualdade de gênero, respeito à propriedade e livre iniciativa, distribuição equitativa de renda, entre outros, estão presentes em uma agenda ampla e repleta de boas intenções. A sua praticidade, entretanto, é limitada justamente pelo fato de ser genérica, muito abrangente e, com frequência, distante das realidades específicas nas quais se tenta implementá-la.

Embora o estudo de Fonseca (2011) trate especialmente da expressão "participação popular", pelo constatado na presente pesquisa, accountability também pode ser classificado como uma buzzword, que, segundo o autor,

é uma expressão em língua inglesa que representa uma palavra ou expressão que estaria na moda, mas cujo significado original foi perdido e cujo uso corrente foi banalizado. A utilização de uma buzzword tem mais efeito no nível da retórica do que na aplicação prática. (Fonseca, 2011:7)

\footnotetext{
${ }^{8} \mathrm{~A}$ apropriação de termos e sua utilização, com constantes ressignificados, faz parte do processo natural de linguagem e comunicação, e esse fator deve ser considerado ao analisar os usos e significados do termo accountability, apesar de fugir do escopo do presente estudo.
} 
Dessa maneira, a aparente dificuldade de tradução do termo accountability pode também ser desinteressante a quem a utiliza de forma vulgar, como forma de legitimar, por meio da linguagem, alguma ação.

Os resultados encontrados neste estudo também vão ao encontro do que Schedler (1999 apud Pinho e Sacramento, 2009) já havia constatado em seus estudos. Para o autor, apesar de o termo accountability ser apropriado e largamente utilizado em todo o mundo por diferentes instituições e atores, acadêmicos ou não, o mesmo ainda continua subexplorado, pois "o seu significado permanece evasivo, com fronteiras indefinidas e estrutura interna confusa" (Schedler, 1999:13 apud Pinho e Sacramento, 2009:1348).

Voltando à análise dos dados, o termo aparece de forma mais expressiva em artigos vinculados à EAESP/FGV (sete artigos, ou 13\%), que possui tradição na pesquisa em administração pública, e publicados pela RAP (12 artigos, ou 23\%). Esse fator indica como o termo accountability é fortemente relacionado a estudos sobre administração pública, e as entidades que trabalham o tema, seja estudando ou publicando, já demonstram enraizamento e se destacam como potenciais centros de disseminação.

Analisando o tratamento dado ao tema accountability nos artigos pesquisados, concluise que os artigos que fazem uma discussão específica sobre a mesma apresentam uma clara confusão sobre o seu significado, sendo identificados diferentes termos para explicá-la. Apesar disso, observa-se que os termos "responsabilização" e "prestação de contas" são os mais citados nas definições. Logo, observa-se que, embora os termos apresentados apareçam com maior frequência nos artigos analisados, concorda-se com Campos (1990) e Pinho e Sacramento (2009) que ainda não é possível traduzir de forma direta o termo accountability e que seu conceito ainda está em construção no Brasil.

No que se refere às abordagens apresentadas pelos artigos, identificou-se que a maior parte utiliza a divisão clássica sugerida por O'Donnell (accountability horizontal e accountability vertical), mesmo que esta seja bastante criticada, e pouco exploram novos conceitos ou sugerem novas abordagens. Assim, constata-se que as demais abordagens encontradas ainda não estão disseminadas na literatura nacional.

Diante do exposto, acredita-se que este estudo contribui para os pesquisadores da área, tendo em vista que, ao apresentar um panorama geral sobre como a accountability vem sendo estudada na literatura brasileira, consegue demonstrar a confusão existente sobre sua significação e apontar os limites de sua utilização.

Além disso, este estudo demonstra que o conceito de accountability no Brasil, apesar de muitas vezes já ser considerado de "domínio público", ainda não está consolidado na literatura, o que aponta para a necessidade de novos estudos para uma fundamentação teórica mais consistente, abrangente e objetiva sobre o tema. Dado que muitas das classificações sobre as formas de accountability se mostraram diferentes apenas na nomenclatura, acredita-se que os estudos precisam avançar nesse sentido, de forma a apontar critérios que distingam melhor essas classificações.

Reconhecendo as limitações deste estudo, sugere-se como futuras pesquisas a utilização desta mesma sistemática de análise considerando uma amostra maior, bem como a extrapo- 
lação para o cenário internacional, de forma a identificar se os resultados apresentados nesta pesquisa podem ser relacionados ao contexto brasileiro ou ao próprio termo.

\section{Referências}

ABRUCIO, Fernando L.; LOUREIRO, Maria R. Finanças públicas, democracia e accountability: debate teórico e o caso brasileiro. In: ARVATE, Paulo R.; BIDERMAN, Ciro. Economia do setor público no Brasil. Rio de Janeiro: Elsevier; Campus, 2004. p. 75-102.

ANDRADE, Eduardo de C. Alternativa de política educacional para o Brasil: School Accountability. Revista de Economia Política, v. 29, n. 4, p. 454-472, 2009.

ARATO, Andrew. Representação, soberania popular, e accountability. Lua Nova, São Paulo, n. 5556, p. 85-103, 2002.

BARACCHINI, Sabrina A. A inovação presente na administração pública brasileira. Revista de Administração de Empresas, v. 42, n. 2, p. 1-6, 2002.

BEVIR, Mark. Governança democrática: uma genealogia. Revista de Sociologia e Política, v. 19, n. 39, p. 103-114, jun. 2011.

BONACIM, Carlos A. G.; ARAUJO, Adriana M. P. de. Gestão de custos aplicada a hospitais universitários públicos: a experiência do Hospital das Clínicas da Faculdade de Medicina de Ribeirão Preto da USP. Revista de Administração Pública, v. 44, n. 4, p. 903-931, 2010.

BONACIM, Carlos A. G.; ARAUJO, Adriana M. P. de. Valor econômico agregado por hospitais universitários públicos. Revista de Administração de Empresas, v. 49, n. 4, p. 419-433, 2009.

BORGES, Thiago B. et al. Desmistificação do regime contábil de competência. Revista de Administração Pública, v. 44, n. 4, p. 877-901, ago. 2010.

BOSCHI, Renato R. Descentralização, clientelismo e capital social na governança urbana: comparando Belo Horizonte e Salvador. Dados, v. 42, n. 4, p. 655-690, 1999.

BRAGA, Sérgio S.; FRANÇA, Andressa S. T.; NICOLÁS, María A. Os partidos políticos brasileiros e a internet: uma avaliação dos websites dos partidos políticos do Brasil. Revista de Sociologia e Política, v. 17, n. 34, p. 183-208, out. 2009.

BUDNIK, Jenny A. et al. La empresa educativa chilena. Educação e Sociologia, v. 32, n. 115, p. 305322, jun. 2011.

CAMPOS, Ana M. Accountability: quando poderemos traduzi-la para o português? Revista de Administração Pública, Rio de Janeiro, v. 24, n. 2, p. 30-50, mar./abr. 1990.

CENEVIVA, Ricardo. Accountability: novos fatos e novos argumentos — uma revisão da literatura recente. In: ENCONTRO DE ADMINISTRAÇÃO PÚBLICA E GOVERNANÇA DA ANPAD, 2006, São Paulo. Anais... São Paulo: Anpad, 2006. 
CHEIBUB, José A.; PRZEWORSKI, Adam. Democracia, eleições e responsabilidade política. Revista Brasileira de Ciências Sociais, v. 12, n. 35, 1997. Disponível em: <www.scielo.br/scielo. php?script=sci_arttext\&pid=S0102-69091997000300004>. Acesso em: 9 fev. 2012.

CLAD. Centro Latino-Americano de Administração para o Desenvolvimento. La responsabilizacion en la nueva gestion pública latinoamericana. Buenos Aires: Clad BID, 2000. Disponível em: <www. clad.org/siare_isis/innotend/control/control-nc.pdf>. Acesso em: 3 jan. 2013.

CORREA, Izabela M. Planejamento estratégico e gestão pública por resultados no processo de reforma administrativa do estado de Minas Gerais. Revista de Administração Pública, Rio de Janeiro, v. 41, n. 3, p. 487-504, maio/jun. 2007.

DA ROS, Luciano. Poder de decreto e accountability horizontal: dinâmica institucional dos três poderes e medidas provisórias no Brasil pós-1988. Revista de Sociologia e Política, v. 16, n. 31, p. 143-160, nov. 2008.

DAHL, Robert. Polyarchy. New Haven; Londres: Yale University Press, 1971.

DENHARDT, Janet V.; DENHARDT, Robert B. The new public service: serving, not steering. Armonk, NY: M. E. Sharpe, 2003.

FIGUEIREDO, Argelina C. Instituições e política no controle do Executivo. Dados, v. 44, n. 4, p. 689-727, 2001.

FONSECA, Igor F. Participação, BUZZWORDS e poder: uma análise crítica da tendência de proliferação de conselhos e comitês locais enquanto instrumentos de gestão ambiental no Brasil. Texto para discussão 1572. Rio de Janeiro: Ipea, 2011.

FONTES FILHO, Joaquim R.; PICOLIN, Lidice M. Governança corporativa em empresas estatais: avanços, propostas e limitações. Revista de Administração Pública, Rio de Janeiro, v. 42, n. 6, p. 1163-1188, 2008.

GAMA NETO, Ricardo B. Minimalismo schumpeteriano, teoria econômica da democracia e escolha racional. Revista de Sociologia e Política, v. 19, n. 38, p. 27-42, fev. 2011.

GOMES, Eduardo G. M. As agências reguladoras independentes e o Tribunal de Contas da União: conflito de jurisdições? Revista de Administração Pública, Rio de Janeiro, v. 40, n. 4, p. 615-630, jul./ago. 2006.

GRANT, Ruth W.; KEOHANE, Robert O. Accountability and abuses of power in world politics. American Political Science Review, v. 99, n. 1, p. 29-43, Feb. 2005.

KENNEY, Charles D. Horizontal accountability: concepts and conflicts. In: MAINWARING, Scott; WELNA, Christopher. Democratic accountability in Latin America. Nova York: Oxford Press, 2003. p. 55-76.

KERCHE, Fábio. Autonomia e discricionariedade do Ministério Público no Brasil. Dados, v. 50, n. 2, p. 259-279, 2007.

LAPERRIERE, Hélène; ZUNIGA, Ricardo. Cuando la comunidad guía la acción: hacia una evaluación comunitaria alternativa. Psicologia e Sociedade, v. 19, n. 3, p. 39-45, 2007. 
LEMOS, Leany B.; LLANOS, Mariana. O Senado e as aprovações de autoridades: um estudo comparativo entre Argentina e Brasil. Revista Brasileira de Ciências Sociais, n. 64, p. 115-138, jun. 2007.

LIMA, Jacob C. Participação, empreendedorismo e autogestão: uma nova cultura do trabalho? Sociologias, Porto Alegre, v. 12, n. 25, p. 158-198, dez. 2010.

MAINWARING, Scott. Introduction: democratic accountability in Latin America. In: MAINWARING, Scott; WELNA, Christopher. Democratic accountability in Latin America. Nova York: Oxford Press, 2003. p. 3-33.

MANIN, Bernard; PRZEWORSKI, Adam; STOKES, Susan C. Eleições e representação. Lua Nova, São Paulo, n. 67, p. 105-138, 2006.

MARIA, João F. A. Desenho institucional e accountability: pressupostos normativos da teoria minimalista. Revista de Sociologia e Política, v. 18, n. 35, p. 27-40, fev. 2010.

MEDEIROS, Marcelo de A. Legitimidade, democracia e accountability no Mercosul. Revista Brasileira de Ciências Sociais, v. 23, n. 67, p. 51-69, 2008.

MEIRELLES, Fernanda; OLIVA, Rafael. Delegação e controle político das agências reguladoras no Brasil. Revista de Administração Pública, Rio de Janeiro, v. 40, n. 4, p. 545-565, jul./ago. 2006.

MELLO, Guiomar N. de. Políticas públicas de educação. Estudos Avançados, São Paulo, v. 5, n. 13, p. 7-47, 1991.

MELO, Marcus A. O viés majoritário na política comparada: responsabilização, desenho institucional e qualidade democrática. Revista Brasileira de Ciências Sociais, v. 22, n. 63, p. 11-29, 2007.

MELO, Marcus A. Política da ação regulatória: responsabilização, credibilidade e delegação. Revista Brasileira de Ciências Sociais, v. 16, n. 46, p. 56-68, 2001.

MIGUEL, Luis F. Accountability em listas abertas. Revista de Sociologia e Política, v. 18, n. 37, p. 183-200, out. 2010.

MIGUEL, Luis F. Impasses da accountability: dilemas e alternativas da representação política. Revista de Sociologia e Política, n. 25, p. 25-38, nov. 2005.

MIGUEL, Luis F. Sorteios e representação democrática. Lua Nova, São Paulo, n. 50, p. 69-96, 2000.

MIGUEL, Luis F. Teoria política feminista e liberalismo: o caso das cotas de representação. Revista Brasileira de Ciências Sociais, v. 15, n. 44, p. 91-102, 2000.

NICOLAU, Jairo. Como controlar o representante?: Considerações sobre as eleições para a Câmara dos Deputados no Brasil. Dados, v. 45, n. 2, p. 219-236, 2002.

O’DONNELL, Guillermo. Accountability horizontal e novas poliarquias. Lua Nova, São Paulo, n. 44, p. 27-54, 1998.

O’DONNELL, Guillermo. Democracia delegativa? Novos Estudos, v. V, n. 31, p. 25-40, 1991.

OLIVEIRA, Luzia H. H. de. Presidencialismos em perspectiva comparada: Argentina, Brasil e Uruguai. Dados, v. 49, n. 2, p. 301-343, 2006. 
OLIVIERI, Cecília. Política, burocracia e redes sociais: as nomeações para o alto escalão do Banco Central do Brasil. Revista de Sociologia e Política, n. 29, p. 147-168, nov. 2007.

OSTRENSKY, Eunice. Soberania e representação: Hobbes, parlamentaristas e levellers. Lua Nova, São Paulo, n. 80, p. 151-179, 2010.

PACHECO, José A. Políticas educativas para o ensino superior na União Europeia: um olhar do lado português. Educação e Sociologia, v. 24, n. 82, p. 17-36, abr. 2003.

PEREIRA, Rita de C. de F. Explorando as possibilidades da meta-análise em marketing. In: ENCONTRO DA ASSOCIAÇÃO NACIONAL DOS PROGRAMAS DE PÓS-GRADUAÇÃO EM ADMINISTRAÇÃO, 28, 2004, Curitiba. Anais... Curitiba: Enanpad, 2004. Disponível em: <www.anpad.org. br/trabalho_popup.php?cod_edicao_trabalho=1477>. Acesso em: 9 fev. 2012.

PERUZZOTTI, Enrique; SMULOVITZ, Catalina. Accountability social: la otra cara del control. In: PERUZZOTTI, Enrique; SMULOVITZ, Catalina (Org.). Controlando la política: ciudadanos y medios en las nuevas democracias latinoamericanas. Buenos Aires: Temas, 2001. p. 23-52.

PINHO, José A. G. Investigando portais de governo eletrônico de estados no Brasil: muita tecnologia e pouca democracia. Revista de Administração Pública, Rio de Janeiro, v. 42, n. 3, p. 471-493, maio/jun. 2008.

PINHO, José A. G.; SACRAMENTO, Ana R. S. Accountability: já podemos traduzi-la para o português? Revista de Administração Pública, Rio de Janeiro, v. 43, n. 6, p. 1343-1368, nov./dez. 2009.

PO, Marcos V.; ABRUCIO, Fernando L. Desenho e funcionamento dos mecanismos de controle e accountability das agências reguladoras brasileiras: semelhanças e diferenças. Revista de Administração Pública, Rio de Janeiro, v. 40, n. 4, p. 679-698, jul./ago. 2006.

POWELL JR. Elections as instrument of democracy. New Haven: Yale University Press, 2000.

PRADO, Otávio. Agências reguladoras e transparência: a disponibilização de informações pela Aneel. Revista de Administração Pública, Rio de Janeiro, v. 40, n. 4, p. 631-646, jul./ago. 2006.

ROCHA, Carlos V. Gestão pública municipal e participação democrática no Brasil. Revista de Sociologia e Política, v. 19, n. 38, p. 171-185, fev. 2011.

RODRIGUES, Gilberto M. A. Relações internacionais federativas no Brasil. Dados, v. 51, n. 4, p. 1015-1034, 2008.

ROMZEK, Barbara S.; INGRAHAM, Patricia. Cross pressures of accountability: initiative, command, and failure in the Ron Brown Plane Crash. Public Administration Review, v. 60, n. 3, p. 240-253, 2000.

SACRAMENTO, Ana R. S. Contribuições da Lei de Responsabilidade Fiscal para o avanço da accountability no Brasil. Cadernos Gestão Pública e Cidadania/CEAPG, São Paulo, v. 10, n. 47, p. 20-47, 2005.

SANO, Hironobu; ABRUCIO, Fernando L. Promessas e resultados da Nova Gestão Pública no Brasil: o caso das organizações sociais de saúde em São Paulo. Revista de Administração de Empresas, v. 48, n. 3, p. 64-80, jul./set. 2008. 
SANTOS, Fabiano; PATRICIO, Inês. Moeda e poder legislativo no Brasil: prestação de contas de bancos centrais no presidencialismo de coalizão. Revista Brasileira de Ciências Sociais, v. 17, n. 49, p. 93-113, 2002.

SANTOS, Maria H. de C. Que Democracia?: uma visão conceitual desde a perspectiva dos países em desenvolvimento. Dados, v. 44, n. 4, p. 729-771, 2001.

SLOMSKI, Valmor et al. A demonstração do resultado econômico e sistemas de custeamento como instrumentos de evidenciação do cumprimento do princípio constitucional da eficiência, produção de governança e accountability no setor público: uma aplicação na Procuradoria-Geral do Município de São Paulo. Revista de Administração Pública, Rio de Janeiro, v. 44, n. 4, p. 933-937, jul./ago. 2010.

SOUZA, Amaury de; LAMOUNIER, Bolívar. O futuro da democracia: cenários político-institucionais até 2022. Estudos Avançados, São Paulo, v. 20, n. 56, p. 43-60, 2006.

STARK, David; BRUSZT, Laszlo. Enabling constraints: fontes institucionais de coerência nas políticas públicas no pós-socialismo. Revista Brasileira de Ciências Sociais, v. 13, n. 36, 1998. Disponível em: <www.scielo.br/scielo.php?script=sci_arttext\&pid=S0102-69091998000100002-

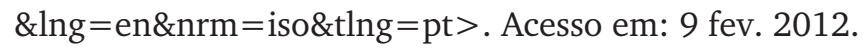

TEIXEIRA, Elenaldo C. Participação cidadã na sociedade civil global. Lua Nova, São Paulo, n. 46, p. 224-235, 1999.

ZAVERUCHA, Jorge. O papel da ouvidoria de polícia. Sociologias, Porto Alegre, n. 20, p. 97-107, dez. 2008.

ZHOURI, Andréa. Justiça ambiental, diversidade cultural e accountability: desafios para a governança ambiental. Revista Brasileira de Ciências Sociais, v. 23, n. 68, p. 97-107, 2008.

Anny Karine de Medeiros é mestre em administração pública e governo pela Escola de Administração de Empresas de São Paulo da Fundação Getulio Vargas (EAESP/FGV) e pesquisadora do Centro de Estudos em Administração Pública e Governo (CEAPG/FGV). E-mail: annykmedeiros@gmail.com.

Tamara Ilinsky Crantschaninov é mestre em administração pública e governo pela Escola de Administração de Empresas de São Paulo da Fundação Getulio Vargas (EAESP/FGV) e pesquisadora do Centro de Estudos em Administração Pública e Governo (CEAPG/FGV). E-mail: tamaracrants@gmail.com.

Fernanda Cristina da Silva é doutoranda em administração pública e governo pela Escola de Administração de Empresas de São Paulo da Fundação Getulio Vargas (EAESP/FGV) e pesquisadora do Centro de Estudos em Administração Pública e Governo (CEAPG/FGV). E-mail: fernanda.cristina@gvmail.br. 
